\title{
KLASTERISASI TINGKAT PENDIDIKAN DI DKI JAKARTA PADA TINGKAT KECAMATAN MENGGUNAKAN ALGORITMA K-MEANS
}

\author{
Ragil Kurniawan ${ }^{1)}$, M. Mukarrobin ${ }^{2)}$, Mahradianur ${ }^{3)}$ \\ ${ }^{1}$ Fakultas Ilmu Komputer Universitas Darwan Ali \\ ragilk032@gmail.com \\ ${ }^{2}$ Fakultas Ilmu Komputer Universitas Darwan Ali \\ yudhaeps99@gmail.com \\ ${ }^{3}$ Fakultas Ilmu Komputer Universitas Darwan Ali \\ mahradianur@gmail.com
}

\begin{abstract}
Abstrak
Pendidikan adalah kebutuhan oleh tiap manusia dalam menjalani kehidupan dan mempersiapkan kualitas Sumber Daya Manusia pada suatu Negara atau bangsa. Penyelenggaraan pendidikan yang berhasil dapat diukur dari kemeretaan jumlah lulusan dari berbagai jenjang pendidikan di berbagai wilayah. Akan tetapi tidak semua wilayah memiliki kemerataan dalam kualitas pendidikannya. Diperlukan adanya pengelompokan serta penggolongan terhadap kualitas pendidikan masyarakat agar memudahkan pemerintah dalam memberikan perhatian khusus terhadap wilayah yang dinilai kurang tersebut. Tetapi, banyaknya jumlah warga dan wilayah mejadi hambatan dalam pengelompokan serta penggolangan tingkatan pendididkan tersebut. Penelitian ini bertujuan untuk menyelesaikan permasalahan tersebut dengan menggunakan metode Clustering algoritma K-Means dan diproses dengan menggunakan software Weka. Pada penilitan ini penulis menggunakan data jumlah tingkat pendidikan masyarakat per kelurahan di DKI Jakarta pada tahun 2020 yang kemudian diolah kembali menjadi per kecamatan. Dari hasil penelitian yang dilakukan oleh penulis akan diperoleh kesimpulan yang menyatakan wilayah mana yang tergolong dalam tingkat pendidikan tinggi dan tingkat pendidikan yang rendah.
\end{abstract}

Keywords: Pendidikan, Clustering, K-Means, Weka

\section{PENDAHULUAN}

Pendidikan adalah kebutuhan oleh tiap manusia dalam menjalani kehidupan dan mempersiapkan kualitas Sumber Daya Manusia pada suatu Negara atau bangsa. Pendidikan akan sangat berpengaruh terhadap masa depan suatu bangsa. Karena Penyelenggaraan pendidikan yang berhasil yang mana dapat diukur dari kemeretaan jumlah lulusan di berbagai jenjang pendidikan mulai dari SD, SLTP, SLTA, hingga Perguruan Tinggi akan menentukan kelanjutan dari kepemerintahan suatu bangsa [1]. Tidak semua wilayah memiliki kemerataan dalam kualitas pendidikan nya, oleh karena itu diperlukan adanya perhatian khusus oleh pemerintah terhadap wilayah yang dinilai kurang dalam kemerataan kualitas pendidikannya. Pengelompokan serta penggolangan tingkatan pendididkan suatu wilayah akan mempermudah pemerintah dalam pertimbangan wilayah mana saja yang memerlukan atensi lebih dalam penyelenggaraan pendidikan. Tetapi, terdapat hambatan dalam mengenali tingkatan pendidikan masyarakat, yaitu dikarenakan banyaknya jumlah warga di banyak wilayah sehingga mempersulit dalam pengelompokan serta penggolangan tingkatan pendididkan suatu wilayah tersebut. Kegiatan pengelompokan meliputi banyak jumlah wilayah beserta masyarakatnya sehingga akan memerlukan waktu yang lama. Dengan adanya pengelompokan tersebut akan dapat dilihat wilayah mana saja yang jumlah lulusannya terbilang rendah atau tinggi pada suatu wilayah. Dari dapat dilihatnya perihal tersebut akan dapat dijadikan sebagai bahan pertimbangan oleh pemerintah, wilayah mana saja yang memerlukan atensi lebih dalam penyelenggaraan pendidikan sehingga tidak tertinggal oleh wilayah lainnya. 
Berdasarkan pada permasalahan tersebut, proses pengelompokan sangat diperlukan untuk mempermudah pemerintah dalam mempertimbangan wilayah mana saja yang memerlukan bantuan berupa bantuan pendidikan. Untuk itu, penulis mengusulkan metode clustering dengan algoritma K-Means terhadap jumlah lulusan dari berbagai jenjang pendidikan mulai dari SD, SLTP, SLTA, hingga Perguruan Tinggi. Pada jurnal ini, pengelompokan dilakukan pada kecamatan yang berada di daerah DKI Jakarta. Metode Clustering akan mempermudah proses pengelompokan data dari tingkat pendidikan setiap wilayah sehingga mempermudah analisis dalam pembuatan pertimbangan wilayah mana saja yang memerlukan bantuan pendidikan.

\section{TINJAUAN PUSTAKA}

\section{Data Mining}

Data Mining adalah proses yang menggunakan teknik statistik, matematika, kecerdasan buatan, dan machine learning untuk mengekstraksi dan mengidentifikasi informasi yang bermanfaat dan pengetahuan yang terkait dari database yang besar [2].

Data mining merupakan proses identifikasi data yang mempunyai potensi kebergunaan sehingga pada akhirnya mudah diinterpretasikan. Tugas dari data mining dibagi menjadi dua, yaitu supervised learning dan unsupervised learning. Supervised Learning membutuhkan pembuatan model untuk melakukan analisis. Contoh dari Supervised Learning yaitu Classification, Statistic Regression, dan Association Rule. Sementara Unsupervised Learning yaitu pembelajaran yang tidak diawasi oleh variabel dan tidak membuat hipotesis sebelum melakukan analisis. Model akan dibuat berdasarkan hasil. Contoh dari Unsupervised Learning adalah Clustering [3].

\section{Clustering}

Salah satu teknik yang dikenal dalam Data Mining yaitu clustering. Pengertian clustering keilmuan dalam Data Mining adalah pengelompokan sejumlah data atau objek ke dalam cluster (group) sehingga setiap dalam cluster tersebut akan berisi data yang semirip mungkin dan berbeda dengan objek dalam cluster yang lainnya [4].

Metode clustering yang paling banyak digunakan ialah metode K-Means clustering. Kelemahan utama dari metode ini adalah hasil yang sensitif terhadap pemilihan pusat cluster awal dan perhitungan solusi lokal untuk mencapai kondisi optimal. Analisis Cluster merupakan teknik multivariat yang mempunyai tujauan utama untuk mengelompokkan objek-objek berdasarkan karakteristik yang dimilikinya. Analisis cluster mengklasifikasi objek sehingga setiap objek yang paling dekat kesamaannya dengan objek lain berada dalam cluster yang sama [5].

\section{K-Means}

K-means adalah salah satu algoritma clustering yang menggunakan metode partisi. K-means adalah algoritma clustering yang membagi masing-masing item data ke dalam satu cluster. Berikut ini adalah langkahlangkah dalam algoritma K-means [6].

Langkah-langkah penelitian adalah sebagai berikut

1) Tentukan jumlah klaster (k) pada data set

2) Tentukan centroid. Penentuan nilai centroid pada tahap awal dilakukan secara random, sedangkan pada tahap iterasi digunakan rumus seperti pada persamaan berikut ini:

$$
V_{k}=\frac{\sum_{i=1}^{N_{i}} X_{i}}{N_{k}}
$$

Keterangan :

$\mathrm{Vk}=$ Centroid pada cluster $\mathrm{ke} \mathrm{k}$

$\mathrm{Xi}=$ Data ke $\mathrm{i}$

$\mathrm{Nk}=$ Banyaknya objek/jumlah data yang menjadi anggota klaster ke $\mathrm{k}$

3) Pada masing-masing record, hitung jarak terdekat dengan centroid. Jarak centroid yang digunakan adalah Euclidean 
Distance, dengan rumus seperti pada persamaan di bawah ini :

$$
D_{E}=\sqrt{\left(x_{i}-s_{i}\right)^{2}+\left(y_{i}-t_{i}\right)^{2}}
$$

Keterangan :

$\mathrm{D}_{\mathrm{E}}=$ Euclidean Distance

$\mathrm{i}$ = Banyaknya Objek

$(\mathrm{x}, \mathrm{y})=$ Koordinat Objek

$(\mathrm{s}, \mathrm{t})=$ Koordinat Centroid

4) Kelompokan objek berdasarkan jarak ke centroid terdekat

5) Ulangi langkah ke-2, lakukan iterasi hingga centroid bernilai optimal

\section{METODE PENELITIAN}

\section{Pengumpulan Data}

Data yang digunakan oleh penulis adalah jumlah tingkat pendidikan masyarakat per keluraha di DKI Jakarta pada tahun 2020. Data tersebut didapat dari website https://data.jakarta.go.id. Atribut asli dari dataset tersebut berjumlah 7 yaitu tahun, nama_provinsi, nama_kabupaten, nama_kecamatan, nama_kelurahan, pendidikan, jumlah. Jumlah data dari dataset tersebut berjumlah 2664 data. Kemudian oleh penulis data tersebutn diolah lagi hingga menjadi 8 atribut dan hanya mencantumkan nama_kecamatan sebagai datanya yang mana berjumlah 44 data.

\section{Clustering}

Dalam penelitian ini metode yang digunakan yaitu metode clustering dengan menggunakan algoritma K-Means dengan nilai k sebanyak 3 klaster yaitu tinggi, sedang dan rendah. Nilai $\mathrm{k}$ tersebut mewakili kualitas pendidikan di wilayah tersebut dan sekaligus akan menjadi bantuan kepada pemerintah dalam mempertimbangkan wilayah mana yang memerlukan bantuan. Fungsi jarak yang digunakan adalah Euclidean Distance. Pada penelitian ini clustering dilakukan menggunakan software Weka 3.9.5.

\section{Visualisasi}

Jurnal Ilmiah “Technologia”
Setelah berhasil didapatkan jumlah anggota pada tiap cluster, selanjutnya akan divisualisasikan persebaran data sesuai cluster yang ditentukam dengan plot pada software Weka 3.9.5. Selanjutnya akan terlihat daftar keanggotaan dari masing-masing cluster yang ditentukan

\section{HASIL DAN PEMBAHASAN}

\section{Hasil Clustering}

Cluster Model yang dihasilkan dari pengelompokan jumlah lulusan dari berbagai jenjang pendidikan mulai dari SD, SLTP, SLTA, hingga Perguruan Tinggi di berbagai wilayah kecamatan provinsi DKI Jakarta dengan algoritma K-Means dapat dilihat dari Gambar 1. Pada Gambar 1 terlihat bahwa jumlah keanggotaan Cluster 0 berjumlah 7 , keanggotaan Cluster 1 terdiri dari 17, dan keanggotaan Cluster 2 terdiri dari 20. Jumlah dari keseluruhan data berjumlah 44. Gambar 2 menampilkan nilai centroid pada tiap cluster dengan atribut yang digunakan adalah Tidak/Belum Sekolah, Belum Tamat SD/Sederajat, Tamat SD/Sederajat, SLTP/Sederajat, SLTA/Sederajat, Diploma I/II, Akademi/Diploma III/S. Muda, Diploma IV/Strata I, Strata II, dan Strata III.

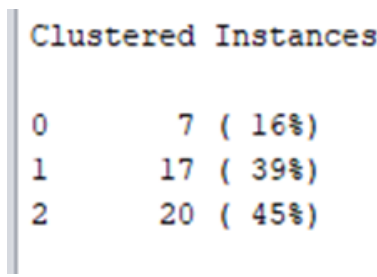

Gambar 1. Jumlah item tiap cluster

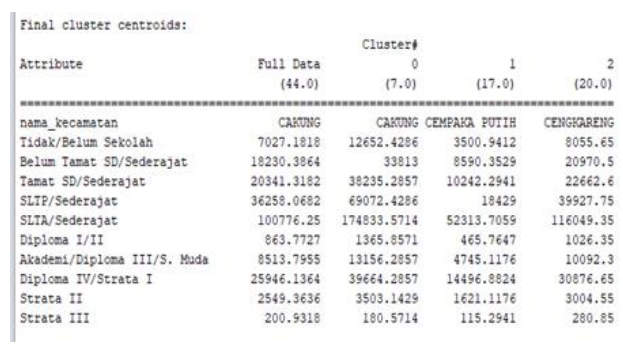

Gambar 2. Nilai centroid

Tabel 1. Daftar anggota tiap klaster

\begin{tabular}{|c|c|c|}
\hline Cluster & Anggota & Jumlah \\
\hline
\end{tabular}




\begin{tabular}{|c|c|c|}
\hline 0 & $\begin{array}{l}\text { CAKUNG, CILINCING, } \\
\text { DUREN SAWIT, } \\
\text { JAGAKARSA, KALI } \\
\text { DERES, KEBON } \\
\text { JERUK, TANJUNG } \\
\text { PRIOK }\end{array}$ & 7 \\
\hline 1 & $\begin{array}{l}\text { CEMPAKA, PUTIH, } \\
\text { GAMBIR, JOHAR } \\
\text { BARU, KEBAYORAN, } \\
\text { BARU, KELAPA } \\
\text { GADING, } \\
\text { KEPULAUAN SERIBU } \\
\text { SELATAN, } \\
\text { MAMPANG, } \\
\text { PRAPATAN, } \\
\text { MATRAMAN, } \\
\text { MENTENG, } \\
\text { PADEMANGAN, } \\
\text { KEPULAUAN SERIBU } \\
\text { UTARA, PANCORAN, } \\
\text { S E N E N, SAWAH } \\
\text { BESAR, SETIA BUDI, } \\
\text { TAMAN SARI, } \\
\text { TANAH ABANG }\end{array}$ & 17 \\
\hline 2 & $\begin{array}{l}\text { CENGKARENG, } \\
\text { CILANDAK, } \\
\text { CIPAYUNG, } \\
\text { CIRACAS, GROGOL } \\
\text { PETAMBURAN, } \\
\text { JATINEGARA, } \\
\text { KEBAYORAN LAMA, } \\
\text { KEMAYORAN, } \\
\text { KEMBANGAN, KOJA, } \\
\text { KRAMATJATI, } \\
\text { MAKASAR, PAL } \\
\text { MERAH, PASAR } \\
\text { MINGGU, PASAR } \\
\text { REBO, } \\
\text { PENJARINGAN, } \\
\text { PESANGGRAHAN, } \\
\text { PULO GADUNG, } \\
\text { TAMBORA, TEBET }\end{array}$ & 20 \\
\hline
\end{tabular}

\section{Analisis Cluster}

Keanggotaan cluster dikelompokkan berdasarkan kesamaannya dengan data lain. Dari analisa hasil clustering didapati bahwa pada cluster 0, merupakan anggota kecamatan dengan tingkat pendidikan yang tergolong rendah. Contohnya, pada kecamatan Cakung, jumlah tidak bersekolah hingga tamat SD sebanyak 107104 orang, terbanyak dibanding kecamatan lain. Pada cluster 0, terdapat kecamatan dengan jumlah Tidak/Belum Sekolah, Belum Tamat SD/Sederajat dan Tamat SD/Sederajat terbanyak dibanding kecamatan lain, yaitu kecamatan Kali Deres sebanyak 17158 untuk Tidak/Belum Sekolah dan 52766 untuk Tamat SD/Sederajat serta kecamatan cakung sebanyak 46387 untuk Belum Tamat SD/Sederajat. Jika dilihat pada jumlah rata-rata pada kecamatan yang ada pada cluster 0 di bagian Tidak/Belum Sekolah mendapat nilai rata-rata sejumlah 12652.43 lebih tinggi dari cluster lain. Pada cluster 2, kecamatan yang masuk pada klaster 2 memiliki lulusan pada jenjang Strata III mencapai 5617 orang dengan rata-rata 280.85 , jauh dibandingkan dengan kecamatan lainnya yang lebih sedikit, terutama pada kecamatan Tambora yang memiliki jumlah lulusan Strata III sebanyak 1919. Dari hasil analisis cluster 0 dan cluster 2 dapat diartikan bahwa cluster 2 memiliki tingkat pendidikan yang tinggi dan cluster 0 memiliki tingkat pendidikan yang rendah. Sedangkan cluster 1 berada di tengahtengah antara cluster 0 dan cluster 2 sehingga bisa simpulkan bahwa cluster 1 berada pada tingkat pendidikan yang sedang.

Berikut adalah visualisasi dari komposisi keanggotaan cluster berdasarkan atribut dan pembagian tingkat tinggi, sedang dan rendah

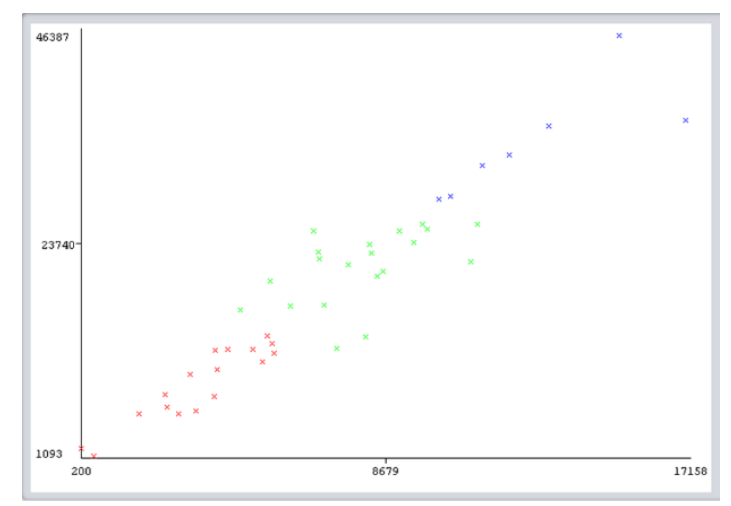

Gambar 3. Tidak/Belum Sekolah (X) dengan Belum tamat SD/Sederajat (Y) 


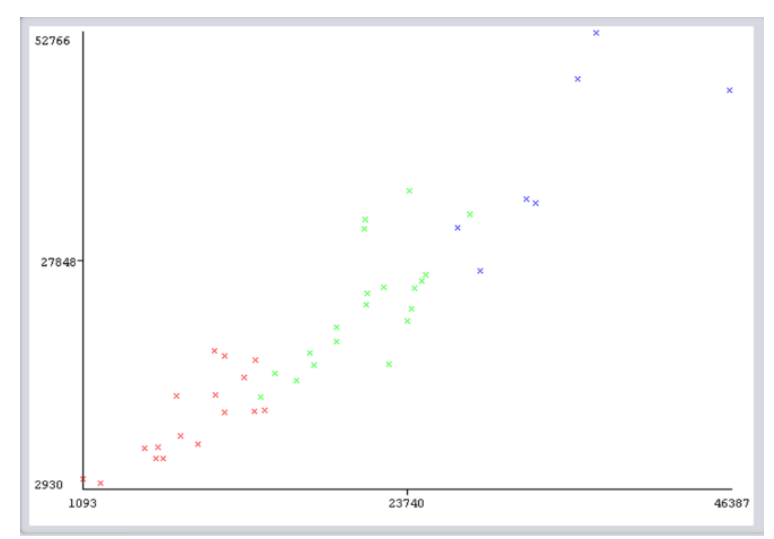

Gambar 4. Belum tamat SD/Sederajat (X) dengan Tamat SD/Sederajat (Y)

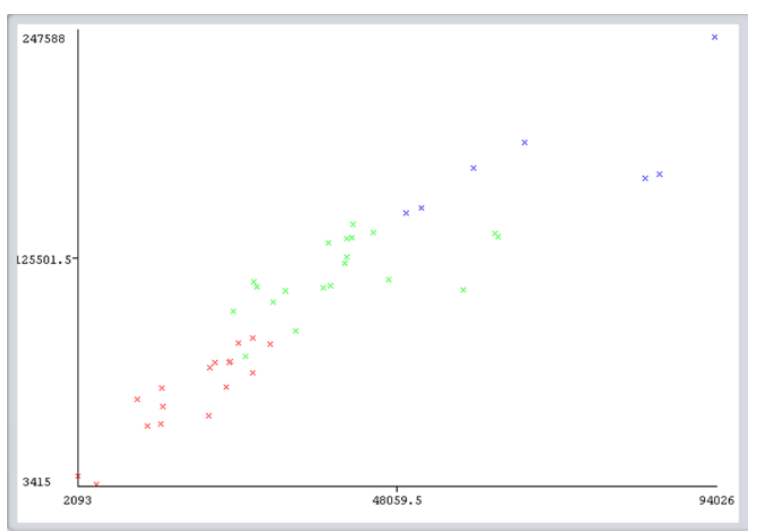

Gambar 5. SLTP/Sederajat (X) dengan SLTA/Sederajat (Y)

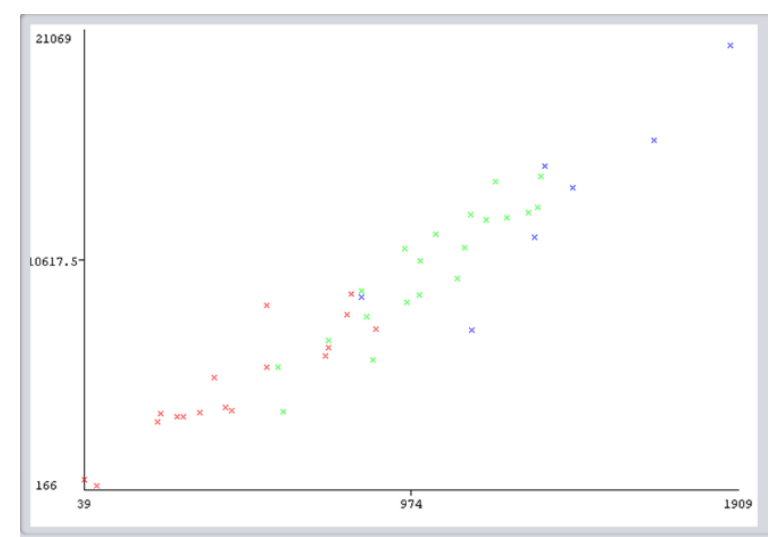

Gambar 6. Diploma I/II (X) dengan Akademi/Diploma III/S. Muda (Y)

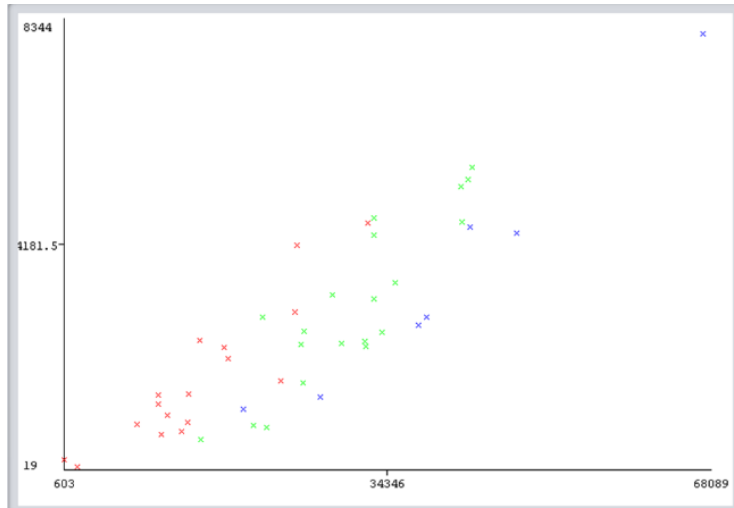

Gambar 7. Diploma IV/Strata I (X) dengan Strata II (Y)

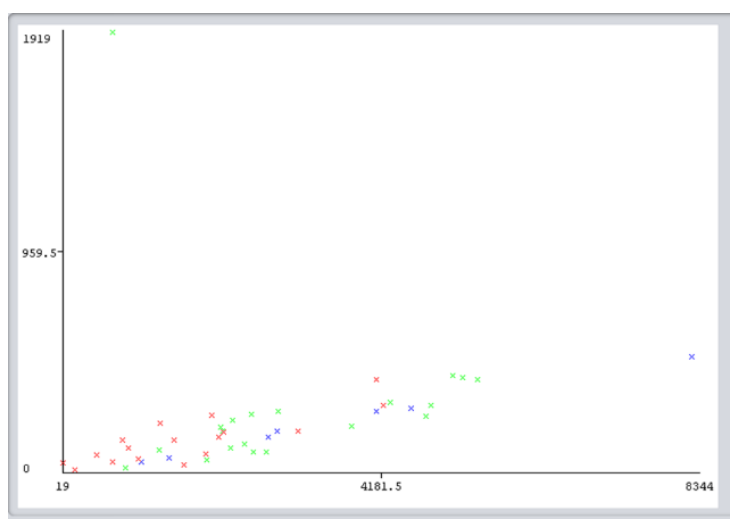

Gambar 8. Strata II (X) dengan Strata III (Y)

\section{KESIMPULAN}

Berdasarkan penelitian yang telah dilakukan dapat disimpulkan bahwa proses clustering data tingkat pendidikan di DKI Jakarta tahun 2020 berjumlah 44 data dengan 3 cluster menghasilkan anggota cluster 0 berjumlah 7 kecamatan, cluster 1 berjumlah 17 kecamatan dan cluster 2 berjumlah 20 kecamatan. Dari hasil proses clustering analissi yang telah dilaksanakan, didapatkan bahwa cluster 2 merupakan kelompok kecamatan yang tergolong dalam tingkat pendidikan yang tinggi sementara cluster 0 merupakan kelompok kecamatan yang tergolong dalam tingkat pendidikan yang rendah. Dari Implementasi dan pembahsan yang di dapat, disimpulkan bahwa kelompok cluster 0 lah yang memerlukan perhatian khusus dari pemerintah berupa bantuan agar tidak tertinggal oleh wilayah lainnya. 


\section{DAFTAR PUSTAKA}

[1] Miftah Andriansyah, Alfatha Fitrah Insan, Muhammad Nizar Yoga Pratama, and Ridho Mahesa, "Pengelompokan Kelurahan di DKI Jakarta Berdasarkan Tingkat Pendidikan Menggunakan Algoritma K-Means,” Jurnal Multimedia, vol. 7, no. 1, pp. 51-57, 2016.

[2] Hendro Pudjiantoro, T. 2011. Penerapan Data Mining Untuk Menganalisa Kemungkinan Pengunduran Diri Calon Mahasiswa Baru. Konferensi Nasional Sistem dan Informatika. 12 November 2011, Bali, Indonesia. Hal. 51-60.

[3] S. David, Atm Saeb, and Khalid Al Rubeaan, "Comparative Analysis of Data Mining Tools and Classification Techniques using WEKA in Medical Bioinformatics," Mendeley, vol. 4, no. 13, pp. 28-39, 2013, Accessed: Aug. 09, 2021.

[4] Tahta Alfina, Budi Santosa, and Ali Ridho Barakbah, "Analisa Perbandingan Metode Hierarchical Clustering, K-Means dan Gabungan Keduanya dalam Cluster Data (Studi Kasus: Problem Kerja Praktek Teknik Industri ITS)," Jurnal Teknik ITS, vol. 1, no. 1, pp. A521-A525, 2012, doi: 10.12962/j23373539.v1i1.1794.

[5] Ediyanto, N. Mara, and Neva Satyahadewi Intisari, "Pengklasifikasian Karakteristik Dengan Metode K-Means Cluster Analysis," Mendeley, vol. 02, no. 2, pp. 133-136, 2013.

[6] Tutik Khotimah, "Pengelompokan Surat Dalam Al Qur'an Menggunakan Algoritma K-Means,” ResearchGate, Apr. 2014. 